\title{
Pemberian Kirinyuh (Cromolaena odorata L.) Sebagai Mulsa Organik Pada Tanaman Kedelai (Glycine max L.) Serta Pengaruhnya Terhadap Sifat Fisika Dan Kimia Tanah
}

\author{
Granting Kirinyuh (Cromolaena odorata L.) As Organic Mulch In Soybean Plants \\ (Glycine max L.) As Well As Its Effects On The Physical And Chemical Properties Of \\ Soil
}

\author{
Nasrullah $^{1}$, Hasanuddin $^{1}$, Syakur $^{1 *}$ \\ ${ }^{1}$ Program Studi Agroteknologi, Fakultas Pertanian, Universitas Syiah Kuala
}

\begin{abstract}
ABSTRAK
Gulma kirinyuh sangat berpotensi untuk dijadikan pupuk organik karena kandungan unsur hara dalam jaringannya yang tinggi. Biomassa kirinyuh memiliki kandungan hara $\mathrm{N}$ $2,65 \%$, $\mathrm{P} 0,53 \%$ dan $\mathrm{K} 1,9 \%$ sehingga dapat dimanfaatkan sebagai sumber hara yang potensial dalam upaya peningkatan produksi kedelai dan perbaikan kesuburan tanah. Penelitian ini bertujuan untuk mengetahui tanah yang sesuai dalam menunjang produksi tanaman kedelai akibat dari penambahan bahan organik kirinyuh. Penelitian ini bertujuan untuk mengetahui tanah yang sesuai dalam menunjang produksi tanaman kedelai akibat dari penambahan bahan organik kirinyuh. Penelitian ini dilakukan dengan menggunakan Rancangan Acak Kelompok (RAK) Faktorial yang terdiri atas 2 (dua) faktor dengan pola $4 \mathrm{x}$ 3 sehingga diperoleh 12 kombinasi perlakuan. Faktor pertama adalah dosis mulsa organik kirinyuh (D), terdiri atas 4 (empat) taraf yaitu: $D_{0}=0$ ton ha ${ }^{-1}, D_{1}=6$ ton ha ${ }^{-1}, D_{2}=12$ ton ha ${ }^{1}, \mathrm{D}_{3}=18$ ton $\mathrm{ha}^{-1}$. Faktor kedua adalah waktu aplikasi mulsa organik kirinyuh (W) terdiri atas 3 (tiga) taraf yaitu saat tanam $\left(\mathrm{W}_{1}\right), 1$ minggu setelah tanam $\left(\mathrm{W}_{2}\right), 2$ minggu setelah tanam $\left(\mathrm{W}_{3}\right)$. Peubah fisika dan kimia tanah yang diamati meliputi bulk density, stabilitas agregat tanah, kapasitas tukar kation dan kejenuhan basa.Hasil penelitian menunjukkan bahwa dosis mulsa organik kirinyuh berpengaruh sangat nyata terhadap sifat fisika tanah yaitu bulk density. Dosis mulsa organik kirinyuh 6 - 18 ton ha ${ }^{-1}$ menurunkan nilai bulk density namun tidak meningkatkan stabilitas agregat tanah. Waktu aplikasi mulsa organik kirinyuh yang awal tidak menunjukkan pengaruhnya terhadap sifat fisika dan kimia tanah yang diamati. Tidak terdapat interaksi antara dosis dan waktu aplikasi mulsa organik kirinyuh terhadap semua peubah yang diamati.
\end{abstract}

Kata kunci : kirinyuh,mulsa organik, fisika tanah, kimia tanah

Abstract. Weed kirinyuh potential to be used as organic fertilizer because the content of nutrient elements in its
high. Biomass kirinyuh contain nutrient $\mathrm{N} 2.65 \%, 0.53 \% \mathrm{P}$ and $\mathrm{K} 1.9 \%$ so that it can be utilized as a source of
potential nutrient in an attempt to increase the production of soybean and improvement of soil fertility. This
research aims to know the appropriate ground support the soybean crop production resulting from the addition of
organic matter kirinyuh. This research aims to know the appropriate ground support the soybean crop production
resulting from the addition of organic matter kirinyuh. This research was performed using Random Design
Group (RAK) Factorial of 2 (two) factors with the 4 x 3 pattern so obtained 12 combination treatment. The first
factor is a dose of organic mulch kirinyuh (D), consisting of four (4) levels, namely: a D0 = 0 ton ha ${ }^{-1}$, D1 = 6
ton ha ${ }^{-1}$, D2 = 12 ton ha ${ }^{-1}$, D $3=18$ ton ha ${ }^{-1}$. The second factor is the time of organic mulch application kirinyuh
(W) consists of 3 (three) level that is when planting (W1), 2 weeks after planting (W2), 2 weeks after planting
(W3). Soil physical and chemical variables were observed include bulk density, soil aggregate stability, cation
exchange capacity and saturation of the base. The results showed that a dose of organic mulch kirinyuh very real
effect against soil physical properties namely bulk density. A dose of organic mulch kirinyuh $6-18$ ton ha ${ }^{-1}$
lowers the values of bulk density but does not increase the stability of soil aggregates. Organic mulch application
time kirinyuh the beginning does not show its effects on the physical and chemical properties of the soil is 
observed. There is no interaction between the dose and time of application of organic mulch kirinyuh against all variables were observed.

Key words: Cromolaena odorata, organic mulch, soil chemistry, soil physics

\section{PENDAHULUAN}

Peningkatan pertumbuhan dan hasil tanaman kedelai dapat dilakukan dengan perbaikan sifat fisik dan kimia tanah. Usaha yang dapat dilakukan untuk memperbaiki sifat fisik dan kimia tanah adalah dengan pemberian bahan organik. Bahan organik tanah memiliki peran dan fungsi yang sangat vital dalam perbaikan sifat-sifat tanah yang meliputi sifat fisika, kimia dan biologi tanah. Bahan organik merupakan sumber energi bagi aktivitas mikrobia tanah dan dapat memperbaiki bulk density tanah, struktur tanah, erosi serta daya mengikat air (Marzuki et al., 2012).

Kirinyuh (Chromolaena odorata L.) yang dijadikan mulsa organik akan berpengaruh terhadap sifat-sifat tanah seperti (1) mengikat unsur hara dan kandungan air dalam tanah terhadap kehilangan karena erosi, banjir atau pencucian (2) mempertahankan kestabilan temperatur dan kelembaban tanah, (3) mengendalikan $\mathrm{pH}$, (4) memperbaiki drainase, (5) mengurangi pemadatan tanah, (6) meningkatkan kapasitas tukar kation, (7) menyediakan habitat yang sesuai bagi mikroorganisme tanah yang menguntungkan dan (8) meningkatkan kandungan bahan organik tanah serta menekan pertumbuhan gulma (Subowo et al., 1990; Abdurachman et al., 2005).

Pemberian 12,5 ton $\mathrm{ha}^{-1}$ mulsa organik kirinyuh pada saat tanam pada tanaman white yam (Dioscorea rotundata Poir) diperoleh kandungan N (0,36 \% ), P (14,9 $\left.\mathrm{mg} \mathrm{kg}^{-1}\right), \mathrm{K}(0,27$ cmol. $\left.\mathrm{kg}^{-1}\right)$, Ca $\left(2,50 \mathrm{cmol} . \mathrm{kg}^{-1}\right)$ dan $\mathrm{Mg}\left(0,62 \mathrm{cmol} \cdot \mathrm{kg}^{-1}\right)$. Hal ini memperjelaskan bahwa pemanfaatan biomassa gulma kirinyuh sangat potensial untuk dikembangkan sebagai sumber pupuk organik dalam perbaikan sifat fisik dan kimia tanah (Agbede et al., 2013). Pemanfaatan mulsa organik kirinyuh selain dapat memperbaiki sifat fisik dan kimia tanah juga dapat berpengaruh terhadap tanaman. Hal ini didukung dengan hasil penelitian Sheku et al. (2012) bahwa dengan pemberian mulsa organik kirinyuh sebanyak 3,75 ton $\mathrm{ha}^{-1}$ dapat meningkatkan jumlah polong kering, bobot kering polong dan hasil biji kering serta berpengaruh juga terhadap diameter batang, jumlah daun, luas daun dan tinggi tanaman kacang tunggak.

Berdasarkan hasil penelitian Rahmawati (2004) pemberian dosis mulsa kirinyuh sebanyak 12 ton ha ${ }^{-1}$ efektif meningkatkan kandungan $\mathrm{N}$ dan $\mathrm{P}$ tanah serta serapan $\mathrm{N}$ dan $\mathrm{P}$ daun dan juga memberikan hasil yang nyata pada bobot kering daun tanaman Desmodunium rensonii. Pemberian mulsa kirinyuh pada tanaman Desmodunium rensonii, pertumbuhan gulma relatif lebih ditekan pada setiap perlakuan pemulsaan yang diberikan dibandingkan dengan kontrol yang lebih cepat tumbuh gulmanya.

\section{METODE PENELITIAN}

\section{Tempat dan Waktu Penelitian}

Penelitian ini telah dilaksanakan di Desa Rumpeet, Kecamatan Krueng Barona Jaya, Aceh Besar dengan titik koordinat 5032'51,27" LU, 95 22'11,25" BT pada ketinggian 6 m diatas permukaan laut. Penelitian ini dilaksanakan dari bulan Juli - Desember 2016.

\section{Bahan dan Alat Penelitian}

Alat yang digunakan dalam penelitian ini adalah ring sampel untuk pengambilan sampel fisika tanah, papan dan palu, cutter, cangkul dan bor untuk pengambilan sampel kimia 
tanah, label nama dan spidol, kantong plastik, karet gelang, kamera, timbangan dan alat-alat laboratorium untuk keperluan analisis sifat fisika dan kimia tanah dilaboratorium.

Bahan yang digunakan dalam penelitian ini adalah brangkasan kirinyuh untuk perlakuan penelitian, benih kedelai varietas Grobogan yang diperoleh dari Balai Penelitian Tanaman Aneka Kacang dan Umbi (Balitkabi) Malang, pupuk N, P dan K, insektisida deltametrhin, tanah yang diambil dari lokasi penelitian dengan sampel tanah yang sudah diberikan perlakuan pemanfaatan mulsa organik kirinyuh dan bahan-bahan kimia untuk keperluan analisis fisika dan kimia tanah dilaboratorium.

\section{Rancangan Penelitian}

Penelitian ini menggunakan Rancangan Acak Kelompok (RAK) pola faktorial dengan 2 faktor dan 2 ulangan. Faktor pertama yaitu dosis mulsa kirinyuh dengan 4 taraf dan faktor kedua adalah waktu aplikasi mulsa kirinyuh dengan 3 taraf sehingga diperoleh 12 kombinasi perlakuan dan 24 unit percobaan

\section{Pelaksanaan Penelitian}

\section{Pengambilan Sampel Tanah Awal}

Pengambilan sampel tanah awal dengan menggunakan metode purposive sampling, sampel tanah diambil pada lima titik yang berbeda yang mewakili $112,29 \mathrm{~m}^{2}$. Pada setiap titik diambil 3 (tiga) macam contoh tanah yaitu (1) tanah utuh, (2) tanah dengan agregat utuh dan (3) tanah terganggu.

\section{Pengolahan Lahan}

Pengolohan lahan dilakukan dua kali, setelah itu dibuat bedeng seluas 1,3 m x 2,7 m sebanyak 24 bedeng (plot).

\section{Persiapan Tanam}

Penanamannya dilakukan dengan cara ditugal sedalam $5 \mathrm{~cm}$ dengan jarak tanam 20 $\mathrm{cm}$ x $30 \mathrm{~cm}$ dan menggunakan tali rapia untuk merapikan titik yang akan ditugal. Selanjutnya setiap lubang tanam diberi 3 dan 4 benih perlubang kemudian 2 minggu setelah tanam, tanamannya ditinggal 2 setiap lubang dan lainnya dipotong.

\section{Pemupukan}

Penggunaan pupuk Urea, SP36, dan $\mathrm{KCl}$ dilakukan secara bersamaan pada saat tanam dengan cara mencampurkan ketiga pupuk tersebut. Dosis pupuk urea yang digunakan sebanyak $50 \mathrm{~kg} \mathrm{ha}^{-1}=17,55 \mathrm{~g} \mathrm{plot}^{-1}$, SP36 $60 \mathrm{~kg} \mathrm{ha}^{-1}=21,06 \mathrm{~g} \mathrm{plot}^{-1}$ dan KCl $70 \mathrm{~kg} \mathrm{ha}^{-1}=$ $24,57 \mathrm{~g} \mathrm{plot}^{-1}$.

\section{Aplikasi Mulsa Organik Kirinyuh}

Mulsa organik kirinyuh berasal dari Desa Ie Seu Um, Kecamatan Mesjid Raya, Kabupaten Aceh Besar. Pengambilan mulsa kirinyuh dilakukan sehari sebelum aplikasi dengan cara memotong bagian batang $20 \mathrm{~cm}$ dari pucuk daun selanjutnya langsung diaplikasikan ke tanaman kedelai sebagai penutup tanah atau mulsa organik menurut masingmasing perlakuan. Untuk kebutuhan dosis mulsa organik kirinyuh setelah dikonversi ke plot yaitu $\mathrm{D}_{1}=2,25 \mathrm{~kg}_{\text {plot }}{ }^{-1}, \mathrm{D}_{2}=4,5 \mathrm{~kg}$ plot- ${ }^{1}, \mathrm{D}_{3}=6,75 \mathrm{~kg} \mathrm{plot}^{-1}$. Total kirinyuh yang dibutuhkan $81 \mathrm{~kg}$ bobot basah.

\section{Pemeliharaan}

Pemeliharaan yang dilakukan meliputi: penyiraman, pengendalian hama dan penyakit. Penyiraman dilakukan pagi dan sore hari. Pengendalian hama dilakukan menggunakan insektisida Deltametrhin sedangkan Penyakit dikendalikan dengan menggunakan fungisida Mankozeb. 


\section{Pengambilan Sampel Tanah Akhir}

Pengambilan sampel tanah akhir dilakukan sehari sebelum panen. Pengambilan sampel tanah utuh untuk menganalisis sifat fisika tanah yaitu bulk density. Pengambilan sampel tanah ini dilakukan dengan menggunakan ring sampel yang diambil pada setiap plot perlakuan. Pengambilan sampel tanah dengan agregat utuh untuk menganalisis kemantapan agregrat tanah dilakukan dengan menggunakan cangkul yang diambil pada setiap plot perlakuan. Pengambilan sampel tanah terganggu atau tanah tidak utuh untuk menganalisis sifat kimia tanah (kapasitas tukar kation dan kejenuhan basa). Pengambilan sampel tanah ini dilakukan dengan menggunakan bor tanah yang diambil pada setiap plot perlakuan.

\section{Pemanenan}

Pemanenan dilakukan pada saat tanaman kedelai berumur 90 hari setelah tanam dengan karakteristik biji sudah keras atau kadar air biji sekitar $14 \%$.

\section{Peubah yang Diamati}

Peubah yanh diamati adalah :

\section{a) Bulk density}

$$
\begin{aligned}
& \mathrm{BD}=\stackrel{\text { Berat kering tanah oven }}{\text { Volume tanah }} \mathrm{g} \mathrm{cm}^{-3} \\
& \text { Volume tanah dapat diketahui dengan rumus: } \pi \mathrm{r}^{2} \mathrm{t} \\
& \pi \quad: 3,14 \\
& \mathrm{r}: \text { jari-jari ring sampel }(\mathrm{cm}) \\
& \mathrm{t}: \text { tinggi ring sampel }(\mathrm{cm})
\end{aligned}
$$

\section{b) Stabilitas agregat tanah}

Untuk menghitung stabilitas agregat tanah ditetapkan secara kuantitatif di laboratorium dengan cara pengayakan kering dan basah menurut metode De Lenheer dan Boodt (1959) yang didasarkan pada perbedaan rata-rata bobot agregat tanah, berdasarkan diameternya pada pengayakan kering dan pengayakan basah maka stabilitas agregat tanah dapat dihitung dengan

\section{1}

menggunakan rumus :

(RBD kering - RBD basah)

c) Kapasitas tukar kation (KTK)

$$
\mathrm{KTK}\left(\mathrm{cmol} \mathrm{kg}^{-1}\right)=\frac{(\text { ml blanko }- \text { ml contoh }) \times N \mathrm{NaOH}}{B K M} \times 100
$$

d) Kejenuhan basa (KB)

$$
\mathrm{KB}=\frac{(\mathrm{K}+\mathrm{Na}+\mathrm{Ca}+\mathrm{Mg})}{K T K} \times 100 \%
$$

\section{HASIL DAN PEMBAHASAN}

\section{Analisis Awal}

Analisis sampel tanah awal dilakukan untuk menentukan beberapa sifat fisika dan kimia tanah sebelum pelaksanaan penelitian. Rata-rata nilai analisis awal disajikan pada Tabel 3. 
Tabel 3. Rata-rata sifat fisika dan kimia tanah awal sebelum penelitian

\begin{tabular}{lllll}
\hline No & \multicolumn{1}{c}{ Parameter Analisis } & \multicolumn{1}{c}{ Satuan } & Rata-rata & \multicolumn{1}{c}{ Kriteria } \\
\hline 1 & Bulk Density & $\mathrm{g} \mathrm{cm}^{3}$ & 1,59 & Sangat tinggi \\
2 & Stabilitas Agregat Tanah & $\%$ & 46,74 & Kurang mantap \\
3 & Kapasitas Tukar Kation & $\mathrm{cmol} \mathrm{kg}^{-1}$ & 37,76 & Tinggi \\
4 & Kejenuhan Basa & $\%$ & 42,04 & sedang \\
\hline
\end{tabular}

Tabel 3 menunjukkan bahwa hasil analisis sifat fisika dan kimia tanah sebelum diberikan perlakuan di lokasi penelitian mempunyai nilai rata-rata yang bervariasi. Rata-rata nilai bulk density tanah $1,59 \mathrm{~g} \mathrm{~cm}^{3}$ (sangat tinggi), rata-rata nilai stabilitas agregat tanah 46,74 $\%$ (kurang mantap), rata-rata nilai kapasitas tukar kation (KTK) $37,76 \mathrm{cmol} \mathrm{kg}^{-1}$ (tinggi) dan rata-rata nilai kejenuhan basa (KB) adalah 42,04 \% dengan kriteria (sedang). Kriteria untuk semua peubah dapat dilihat pada Lampiran 8, 9 dan 10.

Tabel 3 juga menunjukkan bahwa tanah di lokasi penelitian mempunyai permasalahan berupa sangat tingginya nilai bulk density atau padatnya tanah tersebut sehingga menyebabkan tanah tersebut sulit ditembus oleh akar tanaman dan sulit meneruskan air. Selain itu Tabel 3 juga menunjukkan beberapa kendala lainnya seperti kurang mantapnya stabilitas agregat tanah yang menyebabkan tanah tersebut rentan akan terjadinya erosi.

\section{Kapasitas Tukar Kation}

Hasil analisis ragam menunjukkan bahwa pemberian mulsa organik kirinyuh dengan dosis dan waktu aplikasi secara mandiri tidak berpengaruh terhadap kapasitas tukar kation dan tidak terdapat interaksi. Rata-rata nilai kapasitas tukar kation disajikan pada Tabel 6.

Tabel 6. Rata-rata nilai kapasitas tukar kation (KTK) akibat pemberian dosis dan waktu aplikasi mulsa organik kirinyuh

\begin{tabular}{cc}
\hline Perlakuan & Kapasitas Tukar Kation (KTK) \\
\hline Dosis $\left(\right.$ ton $\left.\mathrm{ha}^{-1}\right)$ & $\ldots \ldots \mathrm{cmol} \mathrm{kg}^{-1} \ldots \ldots$ \\
\hline 0 & 37,76 \\
6 & 41,87 \\
12 & 40,80 \\
18 & 39,93 \\
\hline Waktu aplikasi & \\
\hline saat tanam & 39,95 \\
1 MST & 40,20 \\
2 MST & 40,12 \\
\hline
\end{tabular}

Keterangan: $\quad-$. MST $=$ minggu setelah tanam.

Tabel 6 juga menjelaskan bahwa waktu aplikasi mulsa organik kirinyuh tidak berpengaruh terhadap kapasitas tukar kation. Hal ini diduga, karena singkatnya waktu aplikasi dalam penelitian ini sehingga bahan organik yang diberikan belum melapuk secara sempurna. Pemberian bahan organik pada tanah memerlukan waktu yang lama agar dapat menunjukkan pengaruhnya terhadap kapasitas tukar kation. Menurut Sri dan Suci (2003) penambahan bahan organik dalam waktu yang singkat tidak akan menunjukkan pengaruhnya terhadap kapasitas 
tukar kation. Waktu 5 tahun belum cukup untuk tanah meningkatkan kapasitas tukar kationnya.

Proses pertukaran kation didalam tanah tidak dapat berjalan lancar dengan sendirinya karena dipengaruhi oleh sifat-sifat tanah lainnya seperti pH tanah. Suntoro (2003), menambahkan penambahan bahan organik yang masih belum matang akan menyebabkan lambatnya proses peningkatan $\mathrm{pH}$ tanah dikarenakan bahan organik masih belum terdekomposisi dengan baik dan masih melepaskan asam-asam organik. Lambatnya proses peningkatan $\mathrm{pH}$ tanah juga berdampak pada proses lambatnya peningkatan kapasitas tukar kation. Hardjowigeno dan Sarwono (2002) juga menambahkan bahwa pada kebanyakan tanah ditemukan pertukaran kation berubah dengan berubahnya $\mathrm{pH}$ tanah. Pada $\mathrm{pH}$ rendah, hanya muatan permanen liat dan sebagian muatan koloid humus organik yang memegang ion yang dapat digantikan melalui pertukaran kation. Dengan demikian KTK tidak mampu dipengaruhi oleh bahan organik secara sempurna pada keadaan $\mathrm{pH}$ yang rendah atau masam.

\section{Kejenuhan Basa}

Hasil analisis ragam menunjukkan bahwa pemberian mulsa organik kirinyuh dengan perlakuan dosis dan waktu aplikasi tidak berpengaruh terhadap kejenuhan basa dan tidak terdapat interaksi. Nilai rata-rata kejenuhan basa $(\mathrm{KB})$ akibat pemberian dosis dan waktu aplikasi mulsa organik kirinyuh tertera pada Tabel 7.

Tabel 7. Rata-rata nilai kejenuhan basa $(\mathrm{KB})$ akibat pemberian dosis dan waktu aplikasi mulsa organik kirinyuh

\begin{tabular}{cc}
\hline Perlakuan & Kejenuhan Basa $(\mathrm{KB})$ \\
\hline Dosis $\left(\right.$ ton $\left.\mathrm{ha}^{-1}\right)$ & $\ldots . .(\%) \ldots .$. \\
\hline 0 & 42,04 \\
6 & 40,07 \\
12 & 41,60 \\
18 & 42,48 \\
\hline Waktu aplikasi & \\
\hline saat tanam & 42,51 \\
1 MST & 42,05 \\
2 MST & 40,08 \\
\hline
\end{tabular}

Keterangan: $\quad$-. MST $=$ minggu setelah tanam

Tabel 7 menunjukkan bahwa pemberian mulsa organik kirinyuh dengan dosis yang tinggi belum mampu menunjukkan pengaruhnya terhadap kejenuhan basa. Hal ini diduga disebabkan oleh tingkat pencucian yang intensif terhadap basa-basa yang ada pada tanah tersebut. Hardjowigeno (2010), menyatakan pemberian bahan organik belum mampu meningkatkan kejenuhan basa karena pada umumnya kation-kation basa tanah mudah tercuci sehingga menyebabkan rendahnya kejenuhan basa. Hal ini didukung dengan data curah hujan yang termasuk kedalam katagori agak basah seperti yang sudah tertera pada Lampiran 20. kejenuhan basa yang rendah maka tanah akan didominasi oleh kation-kation masam dan semakin sedikit jumlah kation-kation basa. Menurut penilitian Purwanto (2012), terbukanya lahan menyebabkan penurunan kandungan bahan organik tanah dan intensifnya pencucian hara oleh air hujan, hal ini mengakibatkan leaching kation-kation basa sehingga menurunkan kejenuhan basa. 
Waktu aplikasi yang awal belum mampu memperlihatkan perbedaan yang signifikan terhadap kejenuhan basa. Hal ini diduga, karena lambatnya proses dekomposisi mulsa organik kirinyuh sehingga bahan organik yang diberikan belum mampu menghasilkan humus organik yang menyebabkan kejenuhan basa rendah. Didukung dengan pernyataan Tan (1991), bahwa bahan organik yang lambat akan proses dekomposisinya maka akan berdampak pada lambatnya bahan organik menghasilkan humus atau koloid organik didalam tanah sehingga kejenuhan basanya rendah karena koloid organik adalah situs pembebasan kation-kation basa dalam tanah. Besar kecilnya pengaruh bahan organik yang diberikan terhadap kimia tanah sangat dipengaruhi oleh cepat lambatnya proses dekomposisi bahan organik itu sendiri sedangkan cepat lambatnya dekomposisi bahan organik dipengaruhi oleh kandungan hara $\mathrm{C} / \mathrm{N}$ pada biomassa bahan organik tersebut. Menurut Kastono (2005), bahan organik dengan $\mathrm{C} / \mathrm{N}$ tinggi (> 15) menunjukkan dekomposisi belum lanjut atau baru mulai. Biomassa kirinyuh mempunyai kandungan hara $\mathrm{C} / \mathrm{N}$ cukup tinggi yaitu 20,82 (Hadi et al. 2000 dalam Erna, 2012). Diperlukan waktu aplikasi yang lebih awal agar bahan organik terdekomposisi secara sempurna sehingga bahan organik yang diberikan dapat bermanfaat dalam perbaikan sifatsifat kimia tanah.

\section{Kesimpulan}

\section{KESIMPULAN DAN SARAN}

Dosis mulsa organik kirinyuh berpengaruh terhadap sifat fisika tanah yaitu bulk density. Dosis mulsa organik kirinyuh 6 - 18 ton ha ${ }^{-1}$ dapat menurunkan bulk density. Waktu aplikasi mulsa organik kirinyuh tidak berpengaruh terhadap sifat fisika dan kimia tanah yang diamati. Tidak terdapat interaksi antara dosis dan waktu aplikasi mulsa organik kirinyuh terhadap semua peubah yang diamati.

\section{Saran}

Perlu dilakukan penelitian lanjutan pemanfaatan mulsa organik kirinyuh dengan perlakuan kirinyuh yang diolah terlebih dahulu sehingga diharapkan mampu meningkatkan nilai stabilitas agregat tanah, kepasitas tukar kation dan kejenuhan basa yang efektif karena ketiga komponen ini sangat penting dalam menjaga kesuburan tanah.

\section{DAFTAR PUSTAKA}

Abdurachman, A., S. Sutomo, dan N. Sutrisno. 2005. Teknologi pengendalian erosi lahan berlereng dalam teknologi pengelolaan lahan kering menuju pertanian produktif dan ramah lingkungan. Puslitbangtanak. Bogor.

Agbede, T. M., A. O. Adekiya, and J. S. Ogeh. 2013. Effects of Chromolaena and Tithonia on soil properties, leaf nutrient composition, growth and yam yield. West African J. Applied Ecology. 21 (1): 16-29.

De Leenheer, L., and M. De Boodt. 1959. Determination of aggregate stability by the change in mean weight diameter. Overdruk Uit Medelingen Van de Staat te Gent. International Symposium on Soil Structure, Ghent, 1958.

Erna, S. 2012. Perkecambahan dan pertumbuhan gulma bayam duri (Amaranthus spinosus L.) pada pemberian ekstrak kirinyuh (Chromolaena odorata L.) R.M. King And H. Robinson. [Skripsi]. Jurusan Biologi. Fakultas Matematika dan Ilmu Pengetahuan Alam. Universitas Sebelas Maret. Surakarta.

Hardjowigeno, S. 2010. Ilmu tanah. Edisi ketiga. PT Medyatama. Sarana Parkasa. Jakarta. 
Hardjowigeno, S. dan H. Sarwono. 2002. Klasifikasi Tanah dan Pedogenesis. Akademika Press. Jakarta.

Kastono, D. 2005. Tanggapan pertumbuhan dan hasil kedelai hitam terhadap penggunaan pupuk organik dan biopestisida gulma siam (Chromolaena odorata L.). J. Ilmu Pertanian. 12(2): $103-116$.

Marzuki, Sufardi, dan Manfarizah. 2012. Sifat fisika dan hasil kedelai (Glycine Max L.) pada tanah terkompaksi akibat cacing tanah dan bahan organik. J. Manajemen Sumberdaya Lahan. 1(1) : 23-31.

Purwanto, M.E. 2012. Perbandingan sifat kimia dan biologi tanah akibat keterbukaan lahan pada hutan reboisasi pinus di Kecamatan Pollung Kabupaten Humbang Hasundutan Sumatera Utara. [Skripsi]. Fakultas Kehutanan. Institut Pertanian Bogor. Bogor.

Rahmawati, A. 2004. Respon pemberian Chromolaena odorata (L.) King dan Robinson dengan pemulsaan dan pembenaman terhadap produksi dan pertumbuhan legume Desmodium rensonii. [Skripsi]. Program Studi Nutrisi dan Makanan Ternak. Fakultas Peternakan Institut Pertanian Bogor. Bogor.

Sheku, K.M., E.N. Johnny, and F.K. Augustine. 2012. Effect of siam weed (Chromolaena odorata) leaf mulch rates on agronomic traits and yield of cowpea in Sierra Leone. Annual Conference Organized. University Society for Academic Advancement (NUSAA), Njala. Sierra Leone.

Sri, N.H.U., dan H. Suci. 2003. Sifat kimia Entisol pada sistem pertanian organik. J. Ilmu Pertanian. 10(2): 63-69.

Subowo, G., J. Subagja, dan M. Sudjadi. 1990. Pengaruh bahan organik terhadap pencucian hara tanah Ultisol Rangkasbitung Jawa Barat. Pemberitaan Penel. Tanah dan Pupuk. 9 : 26-31.

Suntoro. 2003. Peranan bahan organik terhadap kesuburan tanah dan upaya pengelolaanya. UNS Press. Surakarta.

Tan, K. 1991. Dasar-Dasar Kimia Tanah. Gajah Mada University Press. Yogyakarta. 